\title{
Evaluation of Emergency Shelter Accessibility Based on the Two-step Floating Catchment Area Method in Changchun
}

\author{
Xiaomeng Zhu ${ }^{1}$, Zhijun Tong ${ }^{1, *}$, Xiaolong Luo ${ }^{2}$, Xiangqian $\mathrm{Li}^{1}$, Pengda Lin ${ }^{1}$, Jiquan Zhang ${ }^{1}$ \\ ${ }^{1}$ School of Environment, Institute of Natural Disaster Research, Northeast Normal University, \\ Changchun 130117, China \\ ${ }^{2}$ Disaster Prevention Research Institute, Kyoto University, Kyoto 611-0011, Japan

\section{基于两步移动搜索法的长春市应急避难场所 可达性评价} \\ 朱晓萌 ${ }^{1}$, 佟志军 ${ }^{1, *}$, 骆晓龙 ${ }^{2}$, 李向前 ${ }^{1}$, 林鹏达 ${ }^{1}$, 张继权 ${ }^{1}$ \\ ${ }^{1}$ 东北师范大学环境学院自然灾害研究所, 长春 130117 , 中国 \\ 2 京都大学防灾研究所巨大灾害研究中心, 京都 611-0011, 日本
}

\begin{abstract}
The balanced layout of emergency shelters, which can be measured by spatial accessibility, is an important componentof the urban disaster prevention and mitigation system. Among the various research methods, the two-step floating catchment area method (2SFCA) is a more comprehensive and convenient way. To address the problems in the 2SFCA method applied in the emergency shelter accessibility, we propose a 2SFCA method coupled with the network analysis method to evaluate the shelter accessibility in Changchun and find the problems of the emergency shelter layout and finally put forward the corresponding planning advice. The results indicate that the equity of the emergency shelter layout is poor in some area of Changchun, and the shelter distribution needs to be adjusted according to the trend of
\end{abstract}

作者简介：朱晓萌（1994-)，女，湖北省黄石人，硕 士研究生, 主要从事城市生态安全评价与管理研究, Email: zhuxm712@nenu. edu. cn.

*通讯作者: 佟志军 (1977-), 男, 辽宁省兴城人, 副 教授, 硕士生导师, 主要从事 $3 \mathrm{~S}$ 技术及其在灾害风险 评价与应急决策等研究, Email:gis@nenu. edu. cn the population and road distribution.

Keywords: emergency shelter; spatial accessibility; network analysis method; two-step floating catchment area method; Changchun

\section{摘要}

应急避难场所的均衡布局是构建城市 防灾减灾体系的重要环节之一, 而空间可达 性能够衡量应急避难场所的空间分布是否 均衡合理。在众多研究方法中, 两步移动搜 索法 (2SFCA) 是一种较全面又简便的方法。 针对应用在避难场所可达性评价中的 $2 \mathrm{SFCA}$ 方法所存在的问题, 本文将网络分析法耦合 入 $2 \mathrm{SFCA}$ 方法来评价长春市应急避难场所可 达性现状，分析其空间分布所存在的问题。 结果表明: 长春市部分地区配置的应急避难 场所资源公平性欠佳, 未来需要根据居民人 口与道路分布的趋势来对避难所空间分布 进行适当调整。

关键字: 应急避难场所; 空间可达性; 网络 分析法; 两步移动搜索法; 长春市 


\section{1. 引言}

城市是人口、交通、工业等各类要素集 聚的主要场所, 所以致灾因素也极为复杂, 任何一种灾害 (如地震、洪水等) 的发生都 会造成巨大的人员与经济损失 [1-3]。为了 应对各类突发性灾害, 规划建设合理的应急 避难场所空间布局，是许多国家构建城市防 灾减灾体系的重要环节之一 [4]。应急避难 场所是在发生突发性灾害之时, 可以容纳避 难人员集中进行救援和避难生活的场所, 一 般要求其具有一定规模与配套应急设施、按 照避难要求建设的建筑工程, 主要包括一些 达到避难疏散要求的公园、绿地、广场、学 校等场所 $[5][6]$ 。

应急避难场所作为一种公共服务设施, 其规模大小、服务范围大小和空间分布等因 素直接关系到避难资源分布是否公平、高效, 其中, 可达性是衡量公共服务设施资源配置 均衡性的重要指标之一 [7]。可达性一般是 指从一个地方到达某个目的地的难易程度, 常用通行时间、距离、费用等指标来表示 [8] [9]。在灾害发生时, 大量的避难人口需 要以最快的速度顺利到达应急避难场所, 而 可达性可用来衡量城市居民到达周边避难 场所的难易程度, 从而可以判断城市避难所 的空间分布是否合理, 为未来的优化布局奠 定基础。

国内外空间可达性的研究主要集中在 城市公园绿地与医疗设施, 而有关应急避难 场所空间可达性的研究案例较少, 且主要来 源于国内的学者。目前应用于避难场所可达 性评价的方法主要有网络分析法 [10]、邻域 法 [11]、两步移动搜索法 [12]等。网络分析 法与邻域法仅仅是从交通距离的角度来衡 量应急避难场所的可达性 $[10,11]$, 但是避 难场所的规划布局不仅要考虑交通距离因 素, 还要考虑其规模大小是否满足周边居民 的避难需求。两步移动搜索法 (Two-step floating catchment area method, 简称 $2 \mathrm{SFCA}$ ) 是一种既考虑了距离阻力因素, 又考 虑到设施供给点与需求者之间供需关系的 方法 $[12,13]$, 所以此方法较适合于应急避 难场所的可达性研究。然而, 目前应用于避 难场所可达性评价的研究中的 2SFCA 方法存
在一个问题: 大部分案例中的距离因素采用 的是欧氏距离 [12-15], 与实际避难情景中 避难人员的出行距离存在有较大的偏差。为 了解决这个问题, 本文将网络分析法与两部 移动搜索法相结合来评价长春市中心城区 避难场所的可达性, 以期更加合理的评价城 市应急避难场所的可达性, 分析其空间分布 所存在的问题, 并且为未来的长春市避难场 所规划布局提供相应的建议。

\section{2. 研究方法}

本文将网络分析法耦合入两步移动搜 索法来评价城市应急避难场所的可达性, 具 体实施过程分为两步:

第一步: 对每个避难所供给点 $\mathrm{j}$, 通过 ArcGIS 10.2 平台中网络分析工具中的服务 区分析来搜索所有离 $\mathrm{j}$ 点避难疏散距离 $\mathrm{d} 0$ 范围内的人口聚集点 $k$, 利用高斯方程对落 在该范围内的每个人口聚集点 $\mathrm{k}$ 的避难人口 数量赋以权重, 再将所有加权后的人口进行 加和, 得到避难所供给点 $\mathrm{j}$ 所有潜在的避难 人口需求量。最后将避难所供给点 $\mathrm{j}$ 的有效 避难席位数量除以潜在的避难人口需求量, 可得出供需比率 $\mathrm{Sj}$ :

$$
S_{j}=\frac{P_{j}}{\sum_{k \in\left\{d_{k j} \leq d_{0}\right\}} G\left(d_{k j}, d_{0}\right) P_{k}}
$$

式中 $P k$ 是人口聚集点 $\mathrm{k}$ 的避难人口数量; $\mathrm{dkj}$ 是从人口聚集点 $\mathrm{k}$ 到避难所供给点 $\mathrm{j}$ 的 最小步行距离, 通过ArcGIS 10.2 平台中网 络分析工具中的 OD 成本矩阵分析来计算; $P \mathrm{j}$ 是避难所供给点 $\mathrm{j}$ 的有效避难席位数量; 距离衰减系数 $G(\mathrm{dkj}, \mathrm{d} 0)$ 是高斯方程, 计算 方法如下:

$G\left(d_{k j}, d_{0}\right)=\left\{\begin{array}{c}\frac{e^{-\left(\frac{1}{2}\right) \times\left(\frac{d_{k j}}{d_{0}}\right)^{2}}-e^{-\left(\frac{1}{2}\right)}}{1-e^{-\left(\frac{1}{2}\right)}}, d_{k j} \leq d_{0} \\ 0 \quad, d_{k j}>d_{0}\end{array}\right.$

第二步：对每个人口聚集点 $i$, 通过网 络分析工具中的服务区分析来搜索所有在 避难疏散距离 $\mathrm{d} 0$ 范围内的避难所供给点 1 , 利用高斯方程对每个落在 do 范围内的避难 所供给点 1 点的供需比 $S \mathrm{j}$ 赋予权重, 再将 这些加权后的供需比率进行加和, 最终得到 $i$ 点的可达性 Ri:

$$
R_{i}=\sum_{l \in\left\{d_{i l} \leq d_{0}\right\}} G\left(d_{i l}, d_{0}\right) S_{j}
$$


式中, S1 表示避难所供给点 1 的供需比率, dil 表示人口聚集点 $\mathrm{i}$ 到避难所供给点 1 的 最小步行距离, 通过网络分析工具中的 $\mathrm{OD}$ 成本矩阵分析组件来计算; Ri 是人口聚集点 $\mathrm{i}$ 的避难所可达性值, 其实际含义是 $\mathrm{i}$ 点的 每个避难人员享有的避难席位数量, 本文假 设各个格网单元内部的避难所可达性是均 匀的; 其他标注与 (1) 式中相同。根据《防 灾避难场所设计规范 (GB51143-2015)》和 《城市抗震防灾规划标准 (GB50413-2007)》 中的相关规定 [5] [16], 本文选取的避难疏 散距离 $\mathrm{d} 0$ 为 $2 \mathrm{~km}$ 。

\section{3. 研究区域与数据来源}

\section{1 研究区概况}

长春市是吉林省省会, 东北地区中心城 市之一, 其市区人口众多, 在发生突发性灾 害时需要快速疏散避灾人口, 所以研究此区 域的避难场所可达性具有重要意义。本文选 取长春市中心城区为研究区域, 包括朝阳区、 南关区、净月区等九个区域 (图 1), 总面积 为 $13593.75 \mathrm{~km} 2$ 。考虑到研究区内的避难人 口也可能受到研究区界外邻近的避难所的 影响, 因此将研究区界周边的应避难场所考 虑在内。

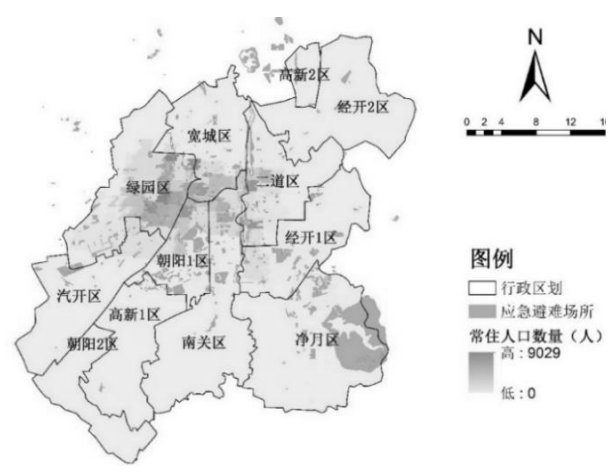

图 1 长春市中心城区人口与应急避难所空间分布

\section{2 数据来源与预处理}

长春市中心城区行政区划数据来源于 《长春市城市总体规划 (2010-2020)》。人 口分布数据源于欧盟全球人居项目 (Global Human Settlement) 提供的 2015 年常住人 口密度的栅格数据, 分辨率为 $250 \mathrm{~m} \times 250 \mathrm{~m}$
(图 1)。本文假设每个网格内的人口是均一 性分布的, 将每个网格的几何中心点作为此 区域的人口聚集点。根据相关规范条例可知 [5] [17], 紧急避难场所应该容纳其搜寻半 径内的所有的灾时常住人口, 固定避难场所 应该容纳其搜寻半径内的灾时常住人口的 $30 \%$, 由此来估算各个避难所周边的人口聚 集点的避难人口数量。长春市路网数据是根 据谷歌地球影像进行目视解译与人工矢量 化得到的, 并且修正了拓扑错误来构建网络 数据集, 同时规定在避难情景下避难人口出 行方式都是步行 (图 2)。

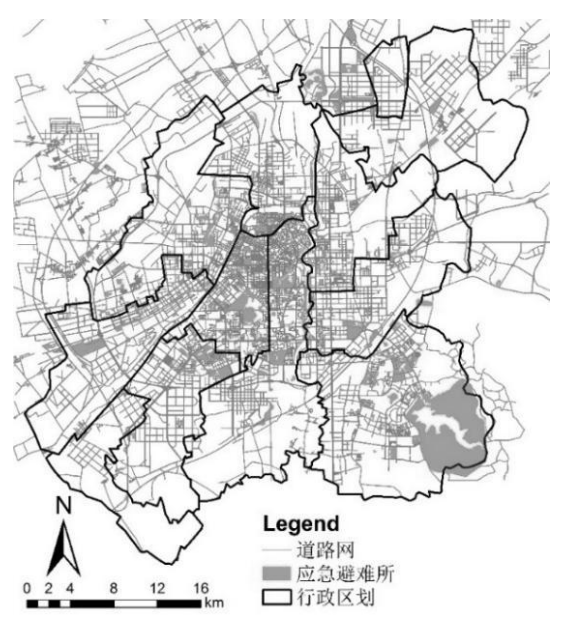

图 2 长春市中心城区道路网与应急避难所 空间分布

应急避难场所数据是以长春市地震局 网站 (http://ccdzj. changchun. gov. cn) 公开的 47 处挂牌避难场所为基础, 目视解 译长春市中心城区 2016 年的 Google Earth 影像, 最终得到应急避难场所的面状矢量数 据 (图 1)。除了挂牌的应急避难场所, 还充 分考虑公园绿地、广场、大型停车场、大型 体育场、部分学校以及小区或者街旁的开敞 绿地等开敞场地作为紧急避难场所设施, 但 不包括其中的水体。每个应急避难场所能提 供的有效避难席位总量是根据《防灾避难场 所设计规范 (GB51143-2015)》中的规定 [5] 的人均有效避难面积来估算的 (表 1 ), 同时 要考虑应急避难场所的管理区面积。管理区 面积以存放救灾物资为主, 一般是 $30 \mathrm{~m} 2 /$ 
千人。最后将带有有效避难席位总量、面积 大小等属性的避难场所面状数据转化成点 状要素, 以便参与可达性计算。

\begin{tabular}{ccc}
\multicolumn{3}{c}{ 表 1 各级避难场避难面积指标 } \\
\hline 避难场所等级 & $\begin{array}{c}\text { 有效避难面 } \\
\text { 积 }\left(\mathrm{hm}^{2}\right)\end{array}$ & $\begin{array}{c}\text { 人均有效避难 } \\
\text { 面积 }\left(\mathrm{m}^{2} / \text { 人) }\right.\end{array}$ \\
\hline $\begin{array}{c}\text { 紧急避难场所 } \\
\text { 固定避难场所 } \\
\text { (短期) }\end{array}$ & $0.2^{\sim} 1.0$ & 0.5 \\
$\begin{array}{c}\text { 固定避难场所 } \\
\text { (中期) }\end{array}$ & $1.0^{\sim} 5.0$ & 3.0 \\
$\begin{array}{c}\text { 固定避难场所 } \\
\text { (长期) }\end{array}$ & $5.0^{\sim} 20.0$ & 4.5 \\
中心避难场所 & $\geqslant 20.0$ & $\geqslant 5.0$ \\
\hline
\end{tabular}

\section{4. 可达性结果分析}

\section{1. 可达性分级与分布特征}

长春市避难场所可达性空间分布结果 （图 3）是通过 ArcGIS 10.2 平台中的自然 断点分级方法来分类的, 而避难所可达性分 为低、较低、较高、高的四种等级 (表 2), 这四种等级可达性区域所占的面积与所占 百分比逐渐减少，大体上呈金字塔式组成结 构。由于避难所可达性实际上等价于人均有 效避难席位数量, 而按照本文计算得到长春 市中心城区人均有效避难席位平均值为 1.42 , 处于高等级的水平之内, 但是处于较 低与低等级的避难所可达性区域面积所占 百分比有 $69.52 \%$, 这说明大部分区域可利用 的避难所低于全市平均水平, 而只有少量的 街道具有高的可达性。总体上讲, 长春市中 心城区的避难所可达性空间分布较不均衡, 呈现出较强的空间极化特征, 需要进一步分 析其可达性分布特征与存在的问题。

表 2 长春市中心城区避难所可达性分级

\begin{tabular}{|c|c|c|}
\hline 可达性等级 & 面积 $\left(\mathrm{km}^{2}\right)$ & $\begin{array}{l}\text { 面积百 } \\
\text { 分比 }\end{array}$ \\
\hline 低 $(<0.123)$ & 5651.88 & $41.58 \%$ \\
\hline $\begin{array}{c}\text { 较低 } \\
\left(0.124^{\sim} 0.538\right)\end{array}$ & 3798.12 & $27.94 \%$ \\
\hline $\begin{array}{c}\text { 较高 } \\
(0.539-1.205)\end{array}$ & 2650.63 & $19.50 \%$ \\
\hline $\begin{array}{c}\text { 高 } \\
(1.206-273.872) \\
\end{array}$ & 1493. 14 & $10.98 \%$ \\
\hline
\end{tabular}

难所可达性空间分布主要有以下三种特征:

（1）长春市中心可达性结果呈现同心 圆结构, 并且以各个应急避难场所为中心, 越靠近中心可达性越高。同心圆的范围与人 口聚集点的搜寻半径范围非常相似, 因为在 2 SFCA 方法中最后一步是根据人口聚集点的 搜寻半径来计算该点的可达性; 且避难人口 一般优先选取离其最近的避难场所, 距离越 远, 距离衰减系数越小, 空间阻力越大, 所 以可达性逐渐降低。这说明了避难疏散距离 对可达性结果有很大的影响, 且人口聚集点 的避难所可达性与两者之间的距离是成反 比的。

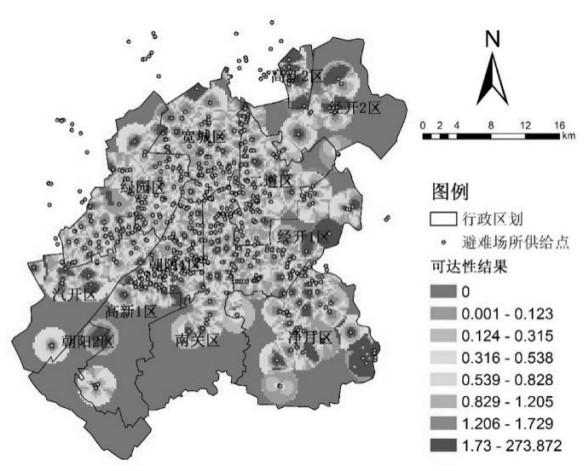

图 3 长春市中心城区避难场所可达性空间分布

（2）长春市城市核心区的避难场所可 达性较高, 但是边缘区的避难场所可达性较 低, 存在有可达性结果均为零的均值区域。 这是因为在城市核心区的避难场所密度较 高, 市中心的避难人口能够较容易获取最近 的避难场所, 但是边缘地区 (如长春市中心 城区的西南部) 的避难所相对较少且分布不 均衡, 此区域中的避难所与大多数居民点的 距离超过了疏散阈值, 所以其避难所可达性 为零。这说明了只有足够数量的避难场所均 匀地分布在合适地点才能满足当地居民点 的避难需求。

(3) 结合图 1 可以发现, 面积较大的 应急避难场所分布的区域呈现可达性较高 的均值斑块, 如净月区东南角的红色斑块。 此区域坐落着净月潭国家森林公园, 是一处 大型的避灾绿地, 因为离避难场所越近可达 性越高, 而此避难所面积大覆盖范围广, 所 
以此处可达性结果较高且相差不大。这说明 了面积较大的避难场所的服务能力相对集 中, 对邻近的居民点的避难所可达性有很大 影响, 但是不能很好的服务距离较远的避难 人口。

总的来说, 长春市中心城区的应急避难 场所可达性结果呈现从市中心向外围逐步 降低的极化特征, 而且避难场所的服务规模、 周边居住人口密度和路网分布对可达性结 果有直接的影响, 因此长春市各区域的避难 所可达性存在较大的差异以及各种分布不 均的问题。

\section{2. 各区可达性现状分析}

长春市各个分区的应急避难场所的可 达性结果统计情况如表 3 所示, 结合表 2、 图 3 分析可知: (1) 净月区的可达性平均值 最大, 处于高等级, 但是存在有大片可达性 值为零的均值区域, 所以净月区的避难所分 布不够均衡, 应该在可达性为零的区域均衡 布局一些应急避难场所, 分散净月潭国家公 园容纳避难人口的压力; (2) 朝阳 2 区、高 新 1 区和南关区的可达性平均值最低, 处于 较低等级, 这是因为分布在朝阳 2 区与高新 1 区的避难场所总共只有 3 处; 而南关区北 部的避难所可达性较好, 但南部几乎没有避 难所分布, 存在可达性为零的均值地块; 根 据《长春市城市总体规划（2017-2020)》可 知未来此三区将会发展南部新城, 其居住人 口将会逐渐增加, 因此未来需要选择合适的 地点建设具有一定规模与服务能力的应急 避难场所; (3) 汽开区与经开 2 区的可达性 均值处于较高等级, 但是也存在有避难场所 分布不均的现象, 其中, 汽开区南部与经开 2 区北部的存在有可达性为零的均值地块, 这些地区几乎没有避难场所的分布, 但考虑 到其现状人口较少且未来人口增加趋势不 明显, 因此可以少量的建设一些综合性避难 场所; (4) 高新 2 区、经开 1 区等余下的六 个行政区可达性均值较高, 同时这几个区域 的避难场所分布比较均匀, 居民能够获取到 较公平的避难场所资源。

总的来说, 净月区、汽开区、南关区的 避难场所资源分布太过集中, 朝阳 2 区、高
新 1 区、经开 2 区的避难场所数量太少, 未 来需要根据这几个区域的人口与道路的分 布趋势来适当的调整应急避难场所的分布, 从而更好的满足居民的避难需求。

表 3 长春市中心城区避难所可达性统计表

\begin{tabular}{ccccc}
\hline 区域 & 最小值 & 最大值 & $\begin{array}{c}\text { 平均 } \\
\text { 值 }\end{array}$ & $\begin{array}{c}\text { 标准 } \\
\text { 差 }\end{array}$ \\
\hline 朝阳 1 区 & 0 & 5.01 & 0.98 & 0.85 \\
朝阳 2 区 & 0 & 21.77 & 0.26 & 1.05 \\
高新 1 区 & 0 & 4.79 & 0.36 & 0.63 \\
高新 2 区 & 0 & 11.78 & 1.75 & 1.91 \\
经开 1 区 & 0 & 23.71 & 1.02 & 1.50 \\
经开 2 区 & 0 & 28.99 & 0.56 & 1.30 \\
南关区 & 0 & 4.06 & 0.37 & 0.59 \\
净月区 & 0 & 273.87 & 5.81 & 26.1 \\
二道区 & 0 & 3.05 & 0.70 & 0.64 \\
绿园区 & 0 & 11.72 & 0.71 & 0.74 \\
宽城区 & 0 & 27.62 & 0.89 & 1.16 \\
汽开区 & 0 & 19.75 & 0.64 & 1.38 \\
\hline 中心城区 & 0 & 273.87 & 1.42 & 10.2 \\
\hline 5. 结论与讨论 & & &
\end{tabular}

5. 结论与讨论

本文综述了国内外应急避难场所可达 性研究现状, 发现了两步移动搜索法应用到 避难所可达性评价的优势与不足之处, 针对 这些问题将网络分析法耦合入两步移动搜 索法, 通过此方法来评价与分析长春市中心 城区应急避难场所的可达性, 研究结果表明: （1）长春市中心城区的应急避难场所的可 达性结果呈现从市中心向外围逐步降低的 空间极化特征, 部分地区的避场所空间分布 不够均衡合理; (2) 净月区、汽开区、南关 区的避难场所资源分布太过集中，在避难所 可达性较高的区域, 在充分考虑避难场所服 务范围和能力以及满足居民避难需求的条 件下, 对这些区域的避难场所布局进行适当 调整, 甚至可以放弃一些综合条件较差的避 难场所; (3) 朝阳 2 区、高新 1 区、经开 2 区的避难场所数量太少, 未来长春市中心城 区南部将发展成南部新城, 此处避难场所资 源不能满足未来逐渐增长的避难人口需求, 因此需要根据其人口与路网分布情况在适 当的地点修建新的应急避难场所来消除服 务盲区。

本文分析与研究了长春市应急避难场 所的可达性现状, 并且提出相应的优化建议 
来改善其目前存在的问题, 但也有一些不足: 一是应急避难场所的面状属性特征对可达 性结果存在有一定的影响, 如果能够得到各 个避难场所的入口及其权重数据, 其可达性 结果会更加精确; 二是没有考虑到不同的居 民群体 (如儿童、老年人等) 步行速度差异 和特殊的避难需求。因此, 今后的研究可以 通过实地调研来获取避难场所的入口数据, 并且结合问卷调查来获取老年人、残疾人等 特殊避难人口的步行速度与避难需求等数 据, 从而更加综合地考虑各种因素对避难场 所可达性的影响, 为未来应急避难场所的规 划与管理提供更加可靠的现状依据。

\section{Acknowledgments}

This research is supported by the Supported by the National Science Foundation of China (41571491 and 41371495); The China Special Fund for Meteorological Research in the Public Interest (GYHY201506001-6); The National Key Technology R\&D Program of China under Grant (2013BAK05B01); The Fundamental Research Funds for the Central Universities of China (2412016KJ046).

\section{致谢}

本研究得到了国家自然科学基金项目 (41571491 和 41371495)、公益性行业（气 象) 科研重大专项 (GYHY201506001-6)、国 家重点技术研发项目 (2013BAK05B01)、中央 高校基本科研业务费专项资金资助 (2412016KJ046)。

\section{参考文献:}

[1] 高晓路, 王坤鹏, 季珏. 城市防灾避难 空间安全性的评价一以北京市紧急避 难场所为例, 人文地理, 2013, (6): 49-54.

[2] Park S J, Kim D W, Kim J H, et al. Future disaster scenario using big data: A case study of extreme cold wave, International Journal of Design \& Nature and Ecodynamics, 2016, 11: 362-369.

[3] Tang B, Wang D, Song Y, et al. Research on the Emergency Shelter Accessibility in
Urban Communities, Journal of Risk Analysis and Crisis Response, 2017, 7(4): 230.

[4] 徐伟, 胡馥妤, 明晓东, 等. 自然灾 害避难所区位布局研究进展, 灾害 学, 2013, 28(4)：143-151.

[5] 中华人民共和国住房和城乡建设 部. GB51143-2015, 防灾避难场所设计 规范, 北京: 中国建筑工业出版社, 2015.

[6] 陈鹏, 张继权, 张立峰, 等. 城市地 震应急避难所适宜性综合评判物元可 拓模型及实证研究, 环境工程, 2016, (S1) : 1132-1136.

[7] 宋正娜, 陈雯, 张桂香, 张蕾. 公共 服务设施空间可达性及其度量方法, 地理科学进展，2010，(10): 1217-1224

[8] 约翰斯顿 R J. 人文地理学词典, 柴彦威, 等译, 北京：商务印书馆, 2004 .

[9] 刘常富, 李小马, 韩东. 城市公园可 达性研究——方法与关键问题, 生态学 报，2010，30(19)：5381-5390.

[10］喜智慧, 徐伟, 袁艺, 等. 农村灾害 避难场所布局规划评价研究——以四 川省小鱼洞镇为例, 灾害学, 2011, 26(3)：115-119.

[11] 李晓玲, 修春亮, 程林, 等. 基于防 灾目标的城市公园空间结构及合理性 评价一邻域法在长春市的应用, 应用 生态学报, 2016, 27 (11) : 3641-3648.

[12] 周爱华, 张景秋, 张远索, 等. GIS 下 的北京城区应急避难场所空间布局与 可达性研究, 测绘通报, 2016, (1) : 111-114.

[13］李孟桐, 杨令宾, 魏冶. 高斯两步移 动搜索法的模型研究一以上海市绿地 可达性为例, 地理科学进展, 2016, (08): 990-996.

[14] 周爱华, 张景秋, 杜姗姗, 何丹, 付 晓. 一种北京城区避难场所可达性评 价方法, 测绘科学, 2017, (01): 88-92+106. 
[15]周爱华, 张景秋, 付晓. 北京城区长 期避难场所空间布局研究, 安全与环境 学报), 2014, (3.

[16］中华人民共和国住房和城乡建设 部. GB50413-2007, 城市抗震防灾规划 标准, 北京: 中国建筑工业出版社, 2007.

[17] 北京市规划委员会. 北京市中心城地 震及应急避难场所 (室外) 规划纲要. http://zhengwu. beijing. gov. cn/gh/ xbqtgh/t1432998. htm 